\title{
MANNOSE INHIBITION OF NITRATE UPTAKE BY WHEAT ROOTS
}

\author{
* Jin-ZHi Li ${ }^{1,2}$, WILLIAM JOHN CRAM $^{1}$, GUANG-YUAN HE ${ }^{1}$ \\ ${ }^{1}$ China-UK HUST-RRes Genetic Engineering and Genomics Joint Laboratory, \\ The Genetic Engineering International Cooperation base of Ministry of Science and Technology, \\ the Key Laboratory of Molecular Biophysics of Ministry of Education, \\ College of Life Science and Technology, \\ Huazhong University of Science \& Technology (HUST) \\ Luoyu Road 1037, Wuhan 430074, China \\ *e-mail:1jzh825@yahoo.com.cn \\ ${ }^{2}$ School of Life Science, Taizhou University \\ Linhai, Zhejiang 317000, China
}

(Received: June 30, 2009. Accepted: January 5, 2010)

\begin{abstract}
The effect of mannose on nitrate uptake was investigated by a new non-invasive technique. Under normal condition, nitrate uptake by wheat (Triticum aestivum L.) roots was about 1-7 $\mu \mathrm{mol} \mathrm{gfwt}^{-1} \mathrm{~h}^{-1}$. After the addition of 10 $\mathrm{mM}$ mannose, net nitrate influx by wheat roots started to decrease and reached a new steady state at $-40 \pm 50 \%$ of the control value after $73 \mathrm{~min}$. After mannose supplied for $2 \mathrm{~h}$, its removal caused net nitrate influx to be recovered to an original rate. Therefore, the inhibition of mannose on nitrate uptake is not due to the onset of programmed cell death because it starts too rapidly and it is reversible, however, it is probably due to Pi and consequent ATP depletion.
\end{abstract}

KEY WORDS: Triticum aestivum L., nitrate uptake, mannose, inhibition.

\section{INTRODUCTION}

In nature, there is no free mannose. Mannose, as a component of polymers fulfilling structural and/or storage roles, is widely distributed in plants. Mannose, similarly to glucose, is phosphorylated by hexokinase. However, in many species mannose-6-phosphate can not be metabolized further because mannose phosphate isomerase is not present and if present its activity is limited both spatially and temporally (Herold and Lewis 1977). Mannose-6-phosphate accumulation is correlated with decrease in ATP, orthophosphate, sucrose and phosphoenolpyruvate (Harris et al. 1986).

Mannose can cause the decrease of [Pi] and ATP, inhibit respiration and proteolysis over a short period (Stenlid 1954, 1971; Loughman 1966). After 24 h, mannose inhibits the increase of weight, causes DNA fragmentation, and initiates programmed cell death in some tissues (Stein and Hansen 1999; Shih et al. 2004). In addition, mannose can cause cytochrome c release from mitochondria in cultured maize cells (Stein and Hansen 1999), lead to oscillations in steady state chlorophyll fluorescence emission

Abbreviations:

Man - mannose; Man-6-P - mannose-6-phosphate
(Harris et al. 1986). In a word, mannose can cause [Pi] and ATP decrease, lead to cell death, inhibit respiration, proteolysis, root growth etc (Stenlid 1954; Loughman 1966; Stein and Hansen 1999). Moreover, the effect of mannose is specific, only D-Man causes a reduction in final fresh weight with concomitant oligonucleosomal fragmentation.

The effects of mannose on roots have been reported, such as the inhibition of respiration, the root growth and $\mathrm{Cl}^{-}$uptake (Stenlid 1954, 1957), subsequently the decrease of ATP. The higher the conc. of mannose is, the lower $\mathrm{Cl}^{-}$ uptake/\% control is (Stenlid 1957). As for the effect of mannose on nitrate uptake (the most important inorganic uptake system in plants), it has not been reported on its change time coursely (Lejay et al. 2003). This paper presents the effects of mannose on nitrate uptake by wheat roots in high time resolution, with a non-invasive new technology (Cram et al. unpublished).

\section{MATERIALS AND METHODS}

\section{Plant culture}

Wheat (Triticum aestivum L. cv. EM18) seedlings were grown in hydroponics culture. The bottom and sides of the container were enclosed in black paper, which can reduce 
light falling on the root system to near zero, and thus minimize algal growth on the roots. The top of the container was covered with black sponge, into which small plastic tubes (two ends were cut) were inserted symmetrically. Wheat seedlings (germination for 3-5 days) were put through small plastic tubes with tweezers, so the plants were fixed on it (grow directly). Finally, air was pumped through the culture solution using an aquarium pump with the inflow tube plugged through the sponge. Subsequently, the water level was replenished every morning and the whole solution replaced regularly.

Wheat plants were grown in one fourth Long Ashton complete nutrient solution at $20^{\circ} \mathrm{C}\left( \pm 2^{\circ} \mathrm{C}\right)$ under $16 \mathrm{~h}$ photoperiod with light flux density of $400 \mu \mathrm{mol} \mathrm{m} \mathrm{m}^{-2} \mathrm{~s}^{-1}$. Plants (20-30 days old) were removed and laid in a large tray with culture solution. Individual roots with their laterals were gently teased apart with a fine wooden needle. Each plant was then transferred to a tray (Perspex) $20 \mathrm{~mm}$ wide, 450 $\mathrm{mm}$ long, with raised sides $5 \mathrm{~mm}$ high, and held a slope of $5^{\circ}$ from the horizontal (at the end of $50 \mathrm{~mm}$ long) (Fig. 1). The roots were aligned along it and covered with fine transparent polythene film. The bottoms of trays enclosed in black paper kept the roots in dark. The shoot was held in a small tube during initial growth. This holder containing the plant was attached to the upper end of the tray, which was bent up at a slightly greater angle as illustrated in Figure 1 . The leaves then lay nearly upright.

Gentle physical disturbance of the plants inhibits nitrate uptake for more than $6 \mathrm{~h}$ (TerSteege et al. 1998). To minimize the transplant shock, we set up the intact wheat plants in the trays at least $14 \mathrm{~h}$ before collecting samples, and treated plants by shifting the flexible tube (by which solution was transported) from one solution to another rather than moving plants. Plants were regularly used for several successive days. Roots and leaves visibly extended from day to day.

\section{Non-invasive measurement of net nitrate influx}

Previously, nitrate uptake was investigated by excised roots. Here, we develop the new non-invasive method to do it. A technique for measuring net nitrate influx by root systems of intact plants growing at a normal rate was used. Non-invasive system in which the intact plants grow at normal rates, the root system can be studied without damaging and nitrate uptake is measured with high time resolution.

Various dilutions of the culture solution were pumped from reservoirs, flowed over the roots from top to bottom of the tray, and pumped out to automatic sample collectors BSA-100. The outflow pump rate was $10 \%$ greater than the inflow to prevent overflow.

Suppose the volume flow over the root system was constant. Net nitrate uptake rate was calculated from measured depletion of the nutrient solution and the volume flow rate $\left(\mathrm{V} / \mathrm{ml} \mathrm{min}^{-1}\right)$, which expressed relative to the fresh weight of the root system measured at the end of the experiment $\left(\mathrm{W}_{\mathrm{R}} / \mathrm{g}\right)$. The nitrate concentration in aliquots of the solution collected after it had flowed over the root system (Cout/mM) was measured by ELIT 8021 nitrate electrode, calibrated regularly against the inflow solution $(\mathrm{Cin} / \mathrm{mM})$ to allow for drift. The volume flow rate regulated by the variable pump BT03 (DG-8), was calculated by the difference between the weight of each test tube before and after collecting solution, then divided by the time. Net nitrate uptake rate was calculated as

$$
\phi_{\text {net }}=\frac{\left(C_{\text {in }}-C_{\text {out }}\right) \cdot V}{W_{R}} \mu \mathrm{mol} \mathrm{gfwt}{ }^{-1} \mathrm{~h}^{-1}
$$

\section{Mannose treatments}

In the experimental room, $\mathrm{Mg}$ lamps were switched on at 06:00 and off at 22:00. Measurement of nitrate uptake was started at 11:00 when net nitrate influx was steady, and mannose was supplied externally after more than $2 \mathrm{~h}$.

\section{RESULTS AND DISCUSSION}

\section{The effect of mannose on net nitrate influx}

The variability between these experiments was substantial, but the main conclusion was statistically significant after the addition of mannose, net nitrate influx started to decrease immediately. Mannose inhibited nitrate uptake rapidly and progressively. By statistics analysis, we know that nitrate appeared to be leaking from the roots after 73 min (reached a new steady state at $-40 \pm 50 \%$ of the control value) (Fig. 2). However, when mannose was removed from the external solution after the treatment for $2 \mathrm{~h}$, net nitrate influx by the roots recovered to their original rate by the next day and maintained it. The reversal showed that the effect of mannose here is not to launch programmed cell death, as might happen after a longer treatment (Shih et al. 2004). The short term inhibition observed after external mannose addition is probably due to $\mathrm{Pi}$ and consequent ATP depletion (Loughman 1966).

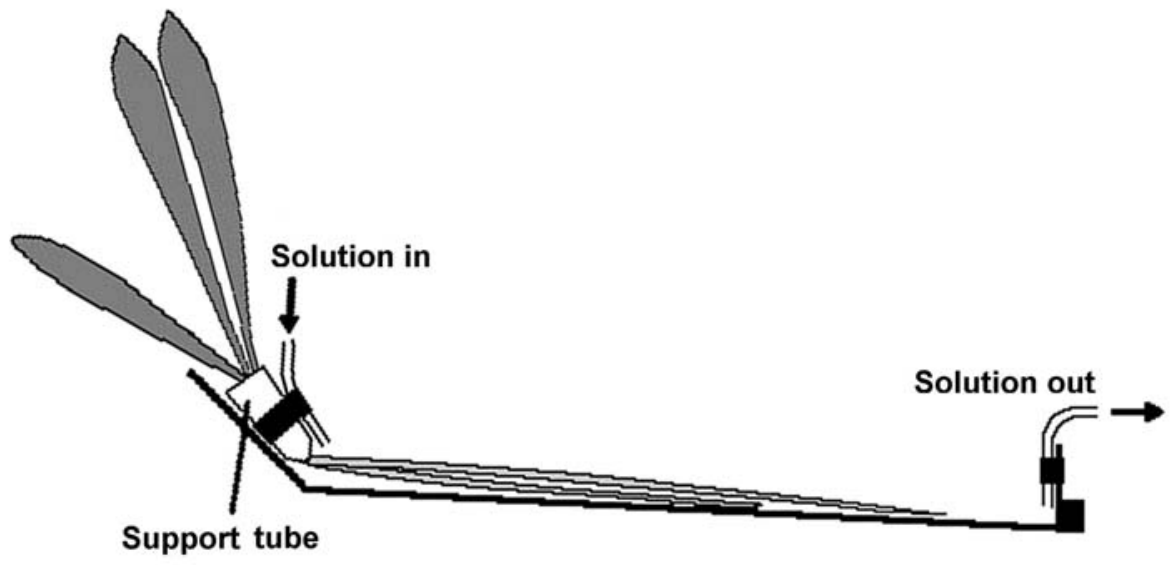

Fig. 1. Set-up for non-invasive measurement of net nitrate influx. 

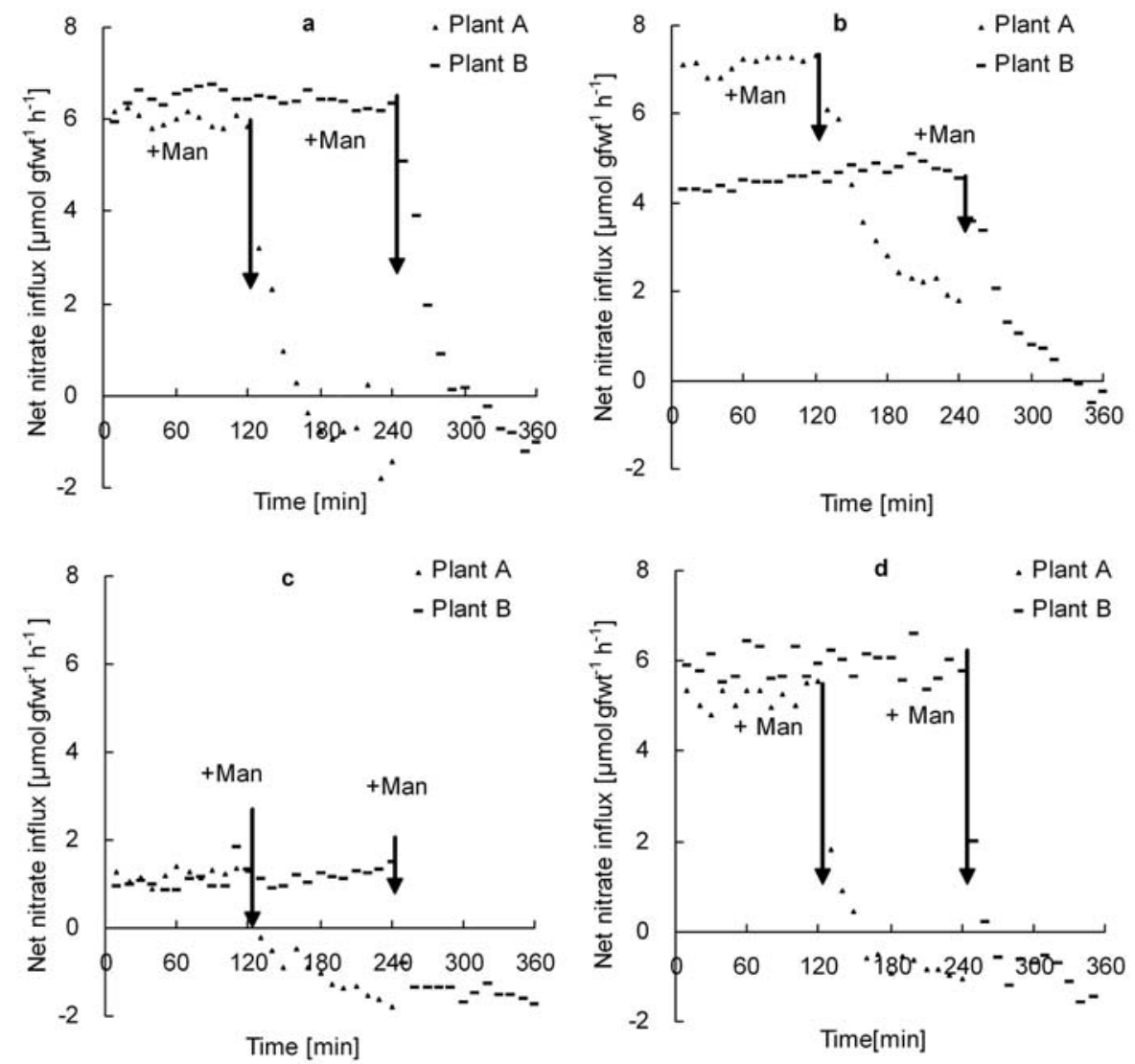

Fig. 2. $10 \mathrm{mM}$ mannose effect on net nitrate influx in the light over $2 \mathrm{~h}$; a-d $-10 \mathrm{mM}$ mannose externally supplied to the roots on 13:00-15:00 to one plant, 15:00-17:00 to another $(10 \mathrm{ml}$ sample was collected every 10 min from 11:00 to 17:00 and data was recorded for $6 \mathrm{~h}$ ). See material and methods for details.

\section{Mechanism of the response to mannose}

Sucrose, glucose, fructose and raffinose can cause the increase of net nitrate influx ( $\mathrm{Li}$ et al. unpublished). However, mannose is an exception, which rapidly inhibits nitrate uptake by roots. After external mannose addition, [Pi] and [ATP] change within less than $1 \mathrm{~h}$ (Loughman 1966) and programmed cell death can be happened $24 \mathrm{~h}$ later (Stein and Hansen 1999; Shih et al. 2004), so the inhibition of nitrate uptake by mannose is not due to the onset of programmed cell death because it starts too rapidly and it is reversible. Therefore it is probably due to Pi and consequent ATP depletion.

Since nitrate uptake is, across plasma membrane by $\mathrm{H}^{+} / \mathrm{NO}_{3}{ }^{-}$co-transport, similar with Pi uptake(Taiz and Zeiger 2002), therefore mechanism of uptake by roots should be the same for Pi and nitrate (Herold and Lewis 1977). We suspect that there are two possibilities by which mannose can affect Pi uptake. First, Mannose affects Pi transport rather than Pi uptake. Pi transport is affected by mannose addition because it consumes Pi (convert into Man-6-phosphate) and leads to Pi decreases in the cell. Second, mannose affects $\mathrm{Pi}$ efflux rather than $\mathrm{Pi}$ influx, because [Pi] decrease causes Pi efflux decrease (Loughman 1966). Based on the above analysis, we presume that mannose inhibits nitrate uptake by affecting nitrate transport or efflux.

\section{Mannose as a new selection agent for transgenic plant}

About 50 selectable marker genes have been tried and only a few are widely used (Miki and McHugh 2004). In addition, antibiotic resistance should be avoided although no adverse effects of marker genes were found by far.

The toxic action of mannose makes it a useful selection agent for the generation of transgenic plants in which Man-
6-P-isomerase gene from the Escherichia coli is used as a resistance marker (Joersbo 1998; Min et al. 2007; Password 2008). Transformants can grow after transferring MPI gene into plant cells, while non-transformants can not grow and eventually die. Moreover, transform frequency, selection efficiency and rooting frequency is higher than selected by kanamycin (Joersbo 1998).

\section{ACKNOWLEDGEMENTS}

Grateful thanks to Prof. Guangxiao Yang, Ms. Junli Chang and Mr. Yuanxi Wu, Bingqiang Li and Lian Jin for help. This work was supported by the "Genetically Modified New Varieties of Major Projects of China" with project of "High-quality new varieties of transgenic wheat cultivation" (2008ZX08002-004).

\section{LITERATURE CITED}

HARRIS G.C., GIBBS P.B., LUDWIG G., UN A., SPRENGNETHER M., KOLODNY N. 1986. Mannose metabolism in corn and its impact on leaf metabolites, photosynthetic gas exchange, and chlorophyll fluorescence. Plant Physiol. 82: 1081-1089.

HEROLD A., LEWIS D.H. 1977. Mannose and green plants: occurrence, physiology and metabolism, and use as a tool to study the role of orthophosphate. New Phytol. 79: 1-40.

JOERSBO M., DONALDSON I., KREIBERG J., PETERSEN S.G., BRUNSTEDT J., OKKELS F.T. 1998. Analysis of mannose selection used for transformation of sugar beet. Mol. breeding 4: 111-117.

LEJAY L., GANSEL X., CEREZO M., TILLARD P., MÜLLER C., KRAPP A., VON WIRÉN N., DANIEL-VEDELE F., GOJON A. 2003. Regulation of root ion transporters by photosyn- 
thesis: Functional importance and relation with hexokinase. Plant Cell 15: 2218-2232.

LOUGHMAN B.C. 1966. The mechanism of absorption and utilization of phosphate by barley plants in relation to subsequent. New Phytol. 65: 388-397.

MIKI B., MCHUGH S. 2004. Selectable marker genes in transgenic plants: applications, alternatives and biosafety. J. Biotechnol. 107: 193-232.

MIN B.W., CHO Y.N., SONG M.J., NOH T.K., KIM B.K., CHAE W.K., PARK Y.S., CHOI Y.D., HARN C.H. 2007. Successful genetic transformation of Chinese cabbage using phosphomannose isomerase as a selection marker. Plant Cell Rep. 26: 337-344.

PASSWORD F. 2008. Chapter 5: Golden Rice 2. Compr. Rev. Food Sci. F. 7 (1): 92-98.

SHIH Y.W., CHOU W.C., LIN Y.M., HUANG D.D., LIU Z.H., HUANG H.J. 2004. Changes in protein tyrosine phosphorylation during mannose and senescence induced cell death in rice. Plant Growth Regul. 42 (3): 1-12.
STEIN J.C., HANSEN G. 1999. Mannose induces an endonuclease responsible for DNA laddering in plant cells. Plant Physiol. 121: 71-79.

STENLID G. 1954. Toxic effects of D-mannose, 2-deoxy-D-glucose and D-glucosamine upon respiration and ion absorption in wheat roots. Plant Physiol. 7: 173-181.

STENLID G. 1957. A comparison of the toxic effects of some sugars upon growth and chloride accumulation in young wheat roots. Physiol. Plantarum 10 (4): 807-823.

STENLID G. 1971. The effect of some inhibitory sugars upon the content of adenosine triphosphate in wheat roots. Physiol. Plantarum 25 (3): 397-401.

TAIZ L., ZEIGER E. (eds). 2002. Plant Physiology. 3rd ed. Sinauer Associates Incorporation Publishers, Sunderland, Massachusetts, pp. 202.

TERSTEEGE M.W., STULEN I., WIERSEMA P.K., PAANS A,J,M, VAALBURG W., KUIPER P.J.C., CLARKSON D.T. 1998. Growth requirement for $\mathrm{N}$ as a criterion to assess the effects of physical manipulation on nitrate uptake fluxes in spinach. Physiol. Plantarum 103: 181-192. 